\title{
Seeing the Watershed Through the Streams
}

Ecology serves as the conceptual framework of my investigation, and maps provide the visual language for my expression. I make prints, drawings, and sculptures that use watersheds as symbols of interconnectedness.

My work leads me into the landscape in multiple ways: walking into the woods and along stream banks awakens an immediate sensory experience of place; composing images with spatial data provides an expansive geographic perspective; repetitive mark-making opens a meditative path that offers insights gained through time spent with sustained focus. Together, these practices define my creative exploration about how we understand and imagine ourselves in relationship to the natural world.

Over the last several years, I've been combining abstract analytical representations of landscapes with perceptual records of the world to examine the intersection of these macro- and micro-scaled interpretations of place. One body of work that has emerged from this inquiry is an ongoing series of watershed maps, created using pigments made from rocks

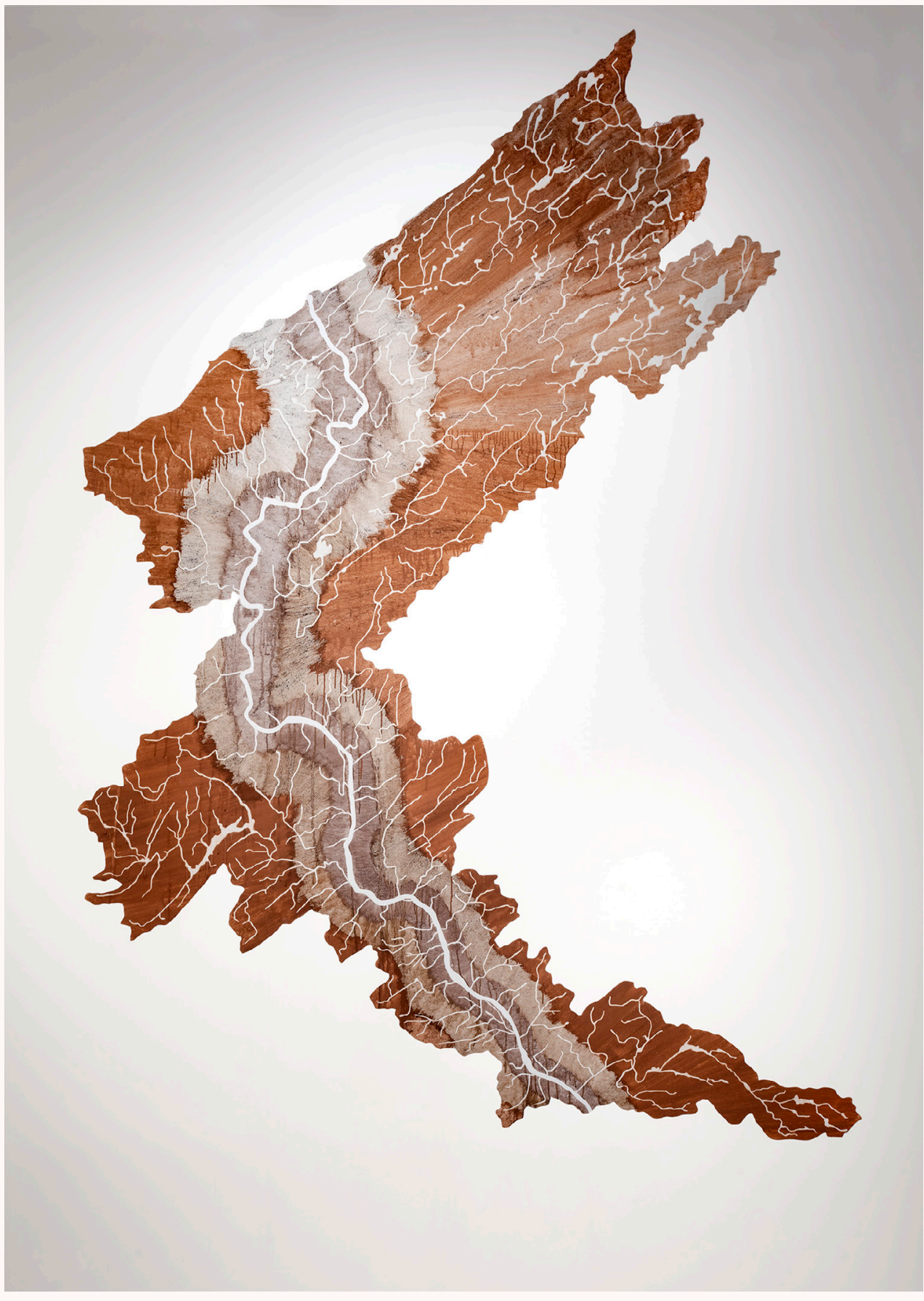

Middle Delaware - Musconetcong Drawing, 2017. 12ft x 8ft, ground rock, water, gum arabic. Temporary installation at Art Yard, Frenchtown, NJ. 


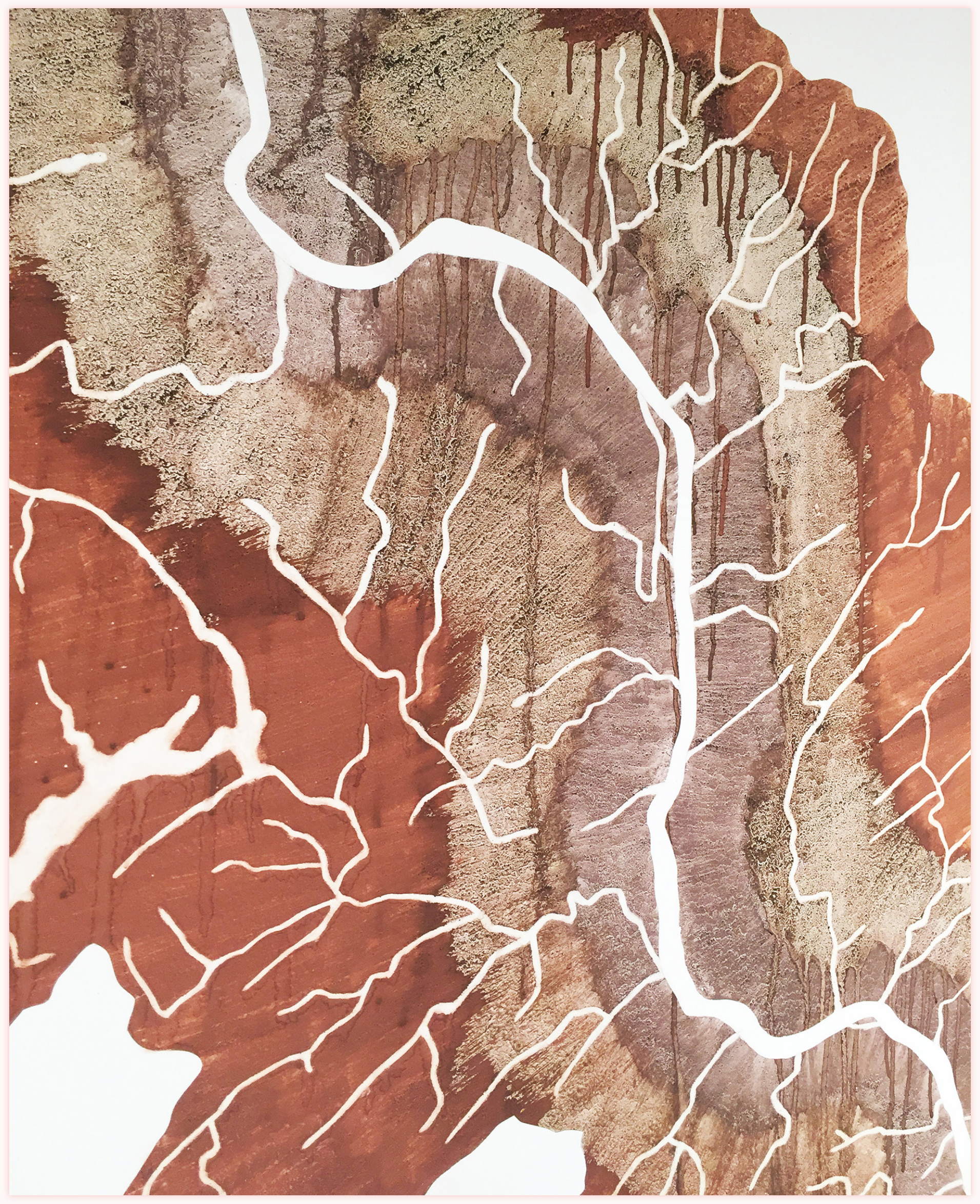

Middle Delaware - Musconetcong Drawing, detail. 


\section{Video: Drawing the Delaware@ ArtYard}

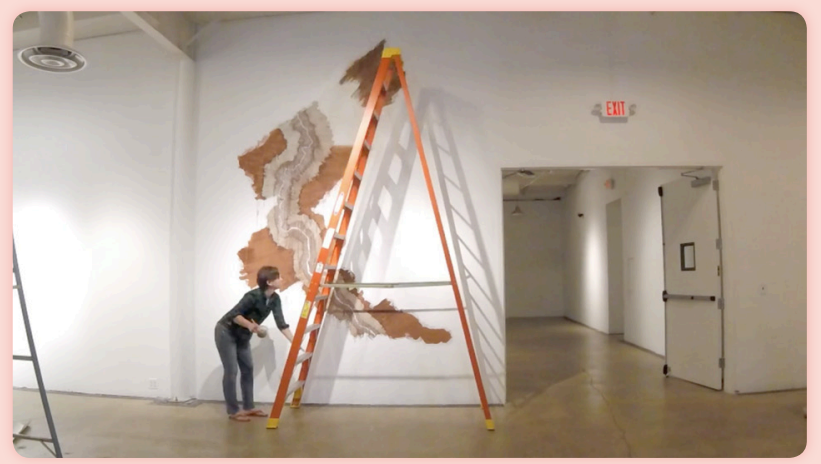

Click to watch a time-lapse of the creation of Middle Delaware - Musconetcong Drawing. collected along lakes and streams. These maps render physical geographies with raw materials filtered through a tangible human connection with nature. In this way, each map is a visual artifact of my experience exploring a particular stream, river, or lake, and holds evidence of time spent wandering in the woods, transforming rocks into pigment, and examining the specific shapes of each basin.

I made the first of these maps in 2005 with sedimentary rocks gathered along the Haw River in the Piedmont region of North Carolina. I ground the stones by hand with a small mortar and pestle, mixed the resulting powdery pigment with river water, and brushed it directly onto the gallery wall in long, horizontal strokes, coating the entire $10 \mathrm{ft}$ tall by $15 \mathrm{ft}$ wide surface in a wash of reddish dust.

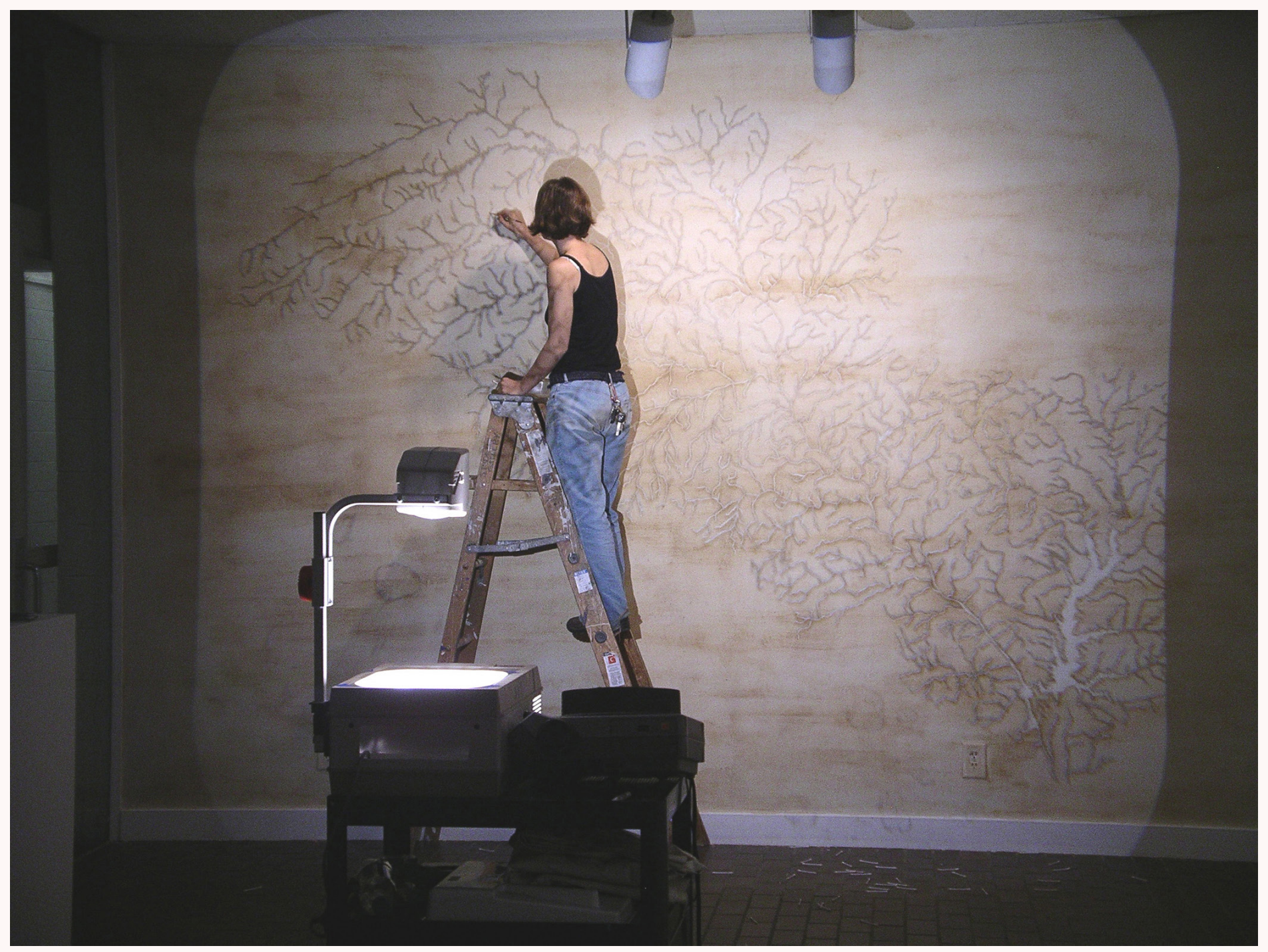

Haw River Drawing, 2005. $10 \mathrm{ft} \times 15 \mathrm{ft}$, ground rock, river water. Temporary installation at Alcott Gallery, UNC Chapel Hill. 


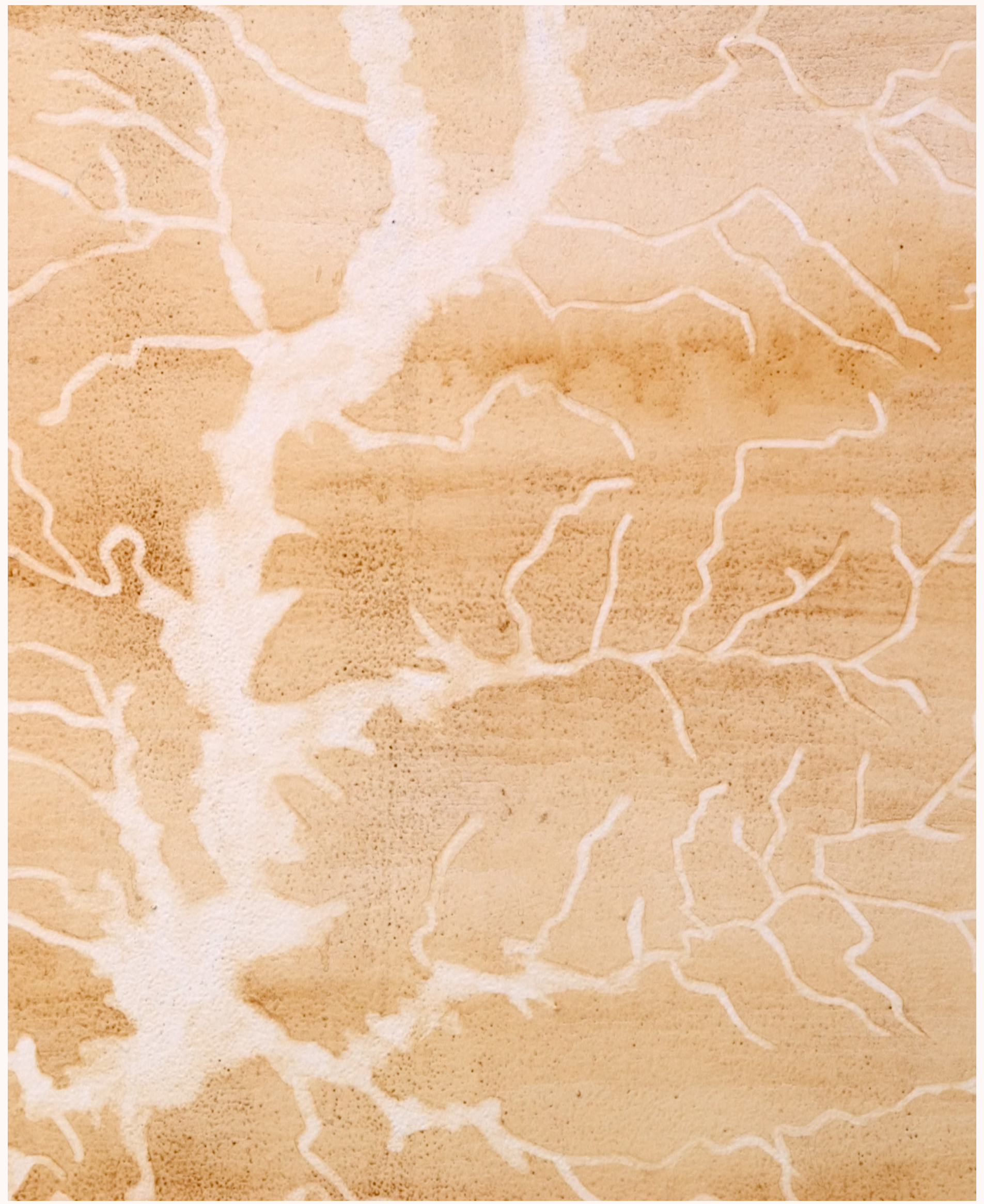

Haw River Drawing, detail. 
While projecting an image of the Haw and its tributaries onto this painted surface, I saturated a small brush in river water and used it to trace each stream, erasing one meandering line after another from the field of rock dust. This process of erasure evokes the way that water marks the landscape by eroding rock and soil in its path from ridge to valley. I've since depicted several other watersheds in this fashion, painting directly onto gallery walls with the most basic substances of rock and water, and then washed them away at the conclusion of each exhibition. I've also developed a more permanent series of works on paper using these site-specific pigments.

Georgia O'Keeffe once said, "It is only by selection, by elimination, and by emphasis that we get at the real meaning of things" (Turner 1999, 1). Each of my maps selectively depicts only the hydrological and/or topographical features within the boundaries of a specific watershed. I've eliminated the markers by which we usually locate and navigate, such as labels, political boundaries, and built structures. These choices emphasize

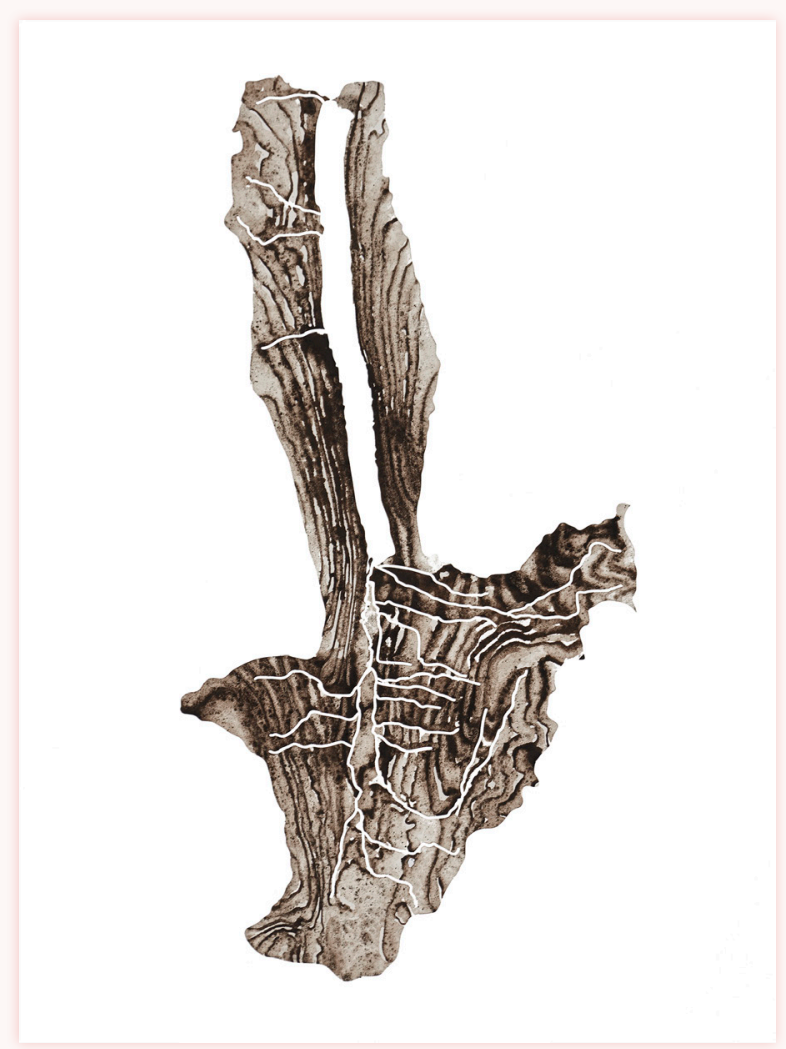

Hemlock Lake, 2017. Sin $\times 11$ in, ground rock, water, and gum arabic on paper.

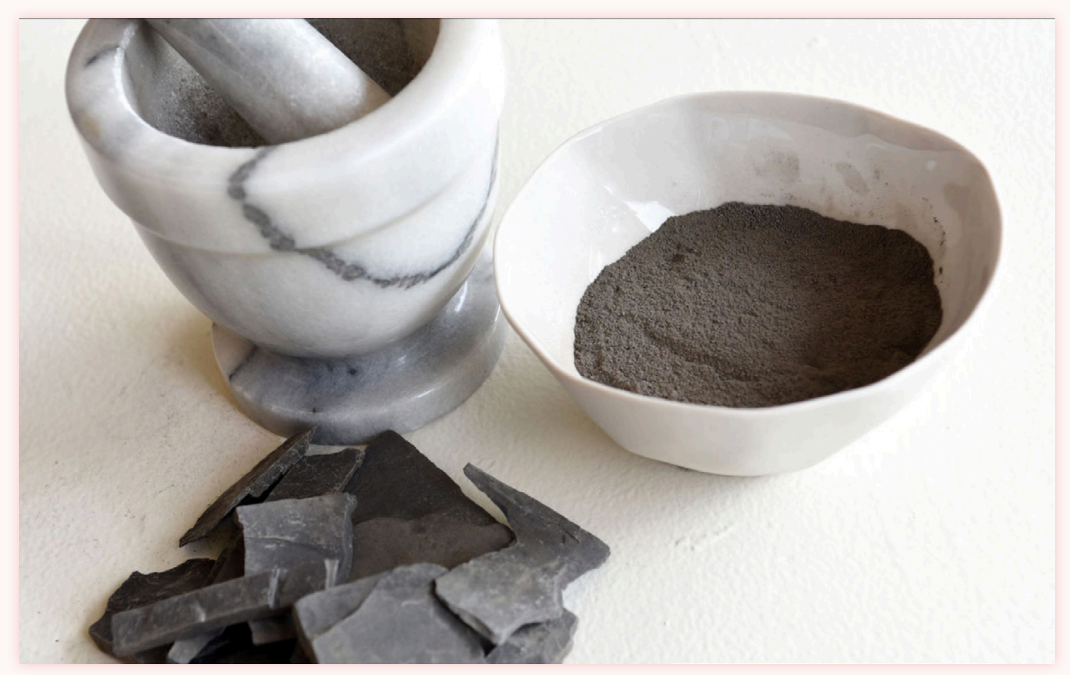

Artist materials. Photo credit: Kevin Rivoli, The Citizen.

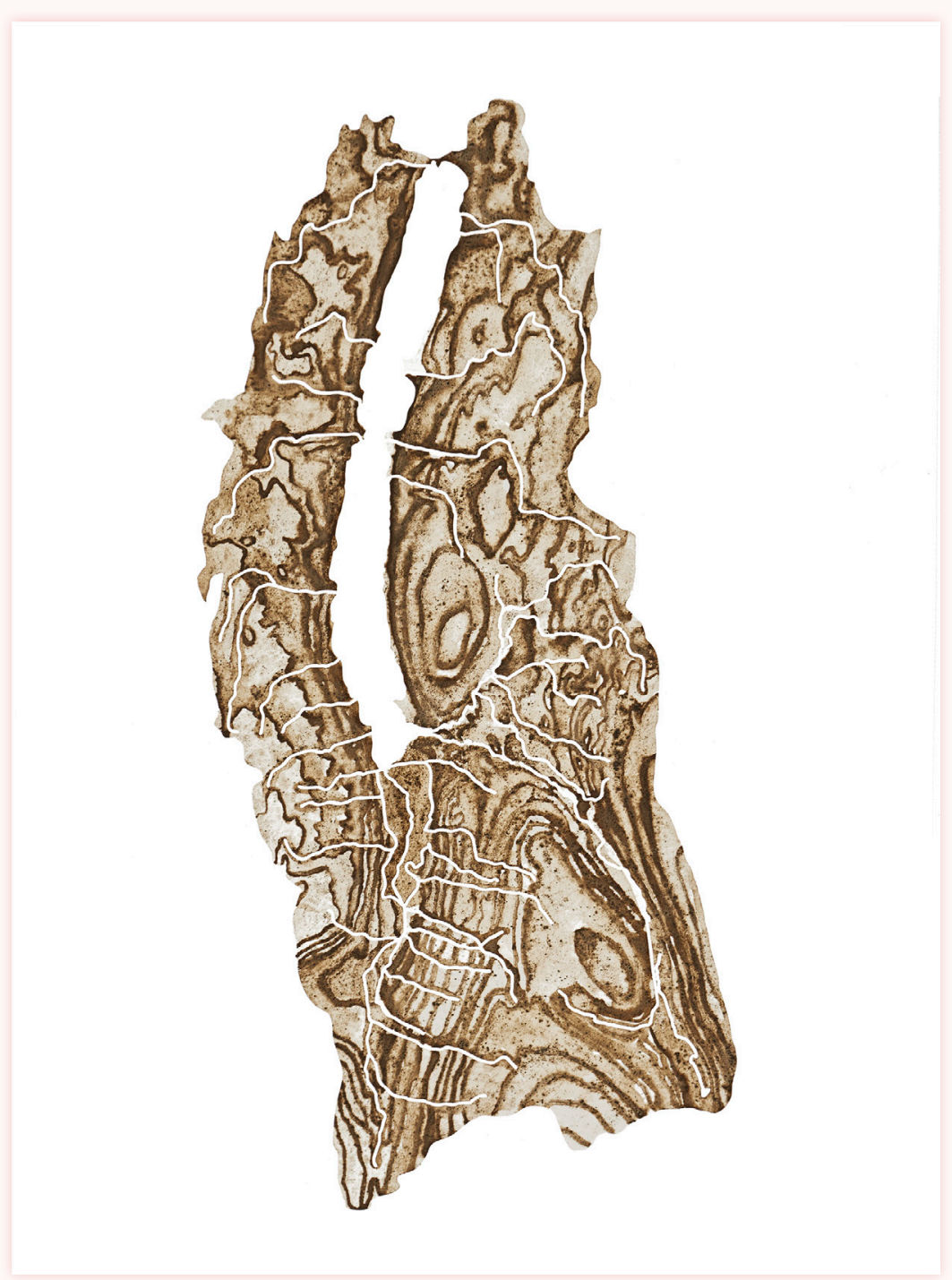

Canadice Lake, 2017. 5in $\times 11$ in, ground rock, water, and gum arabic on paper. 


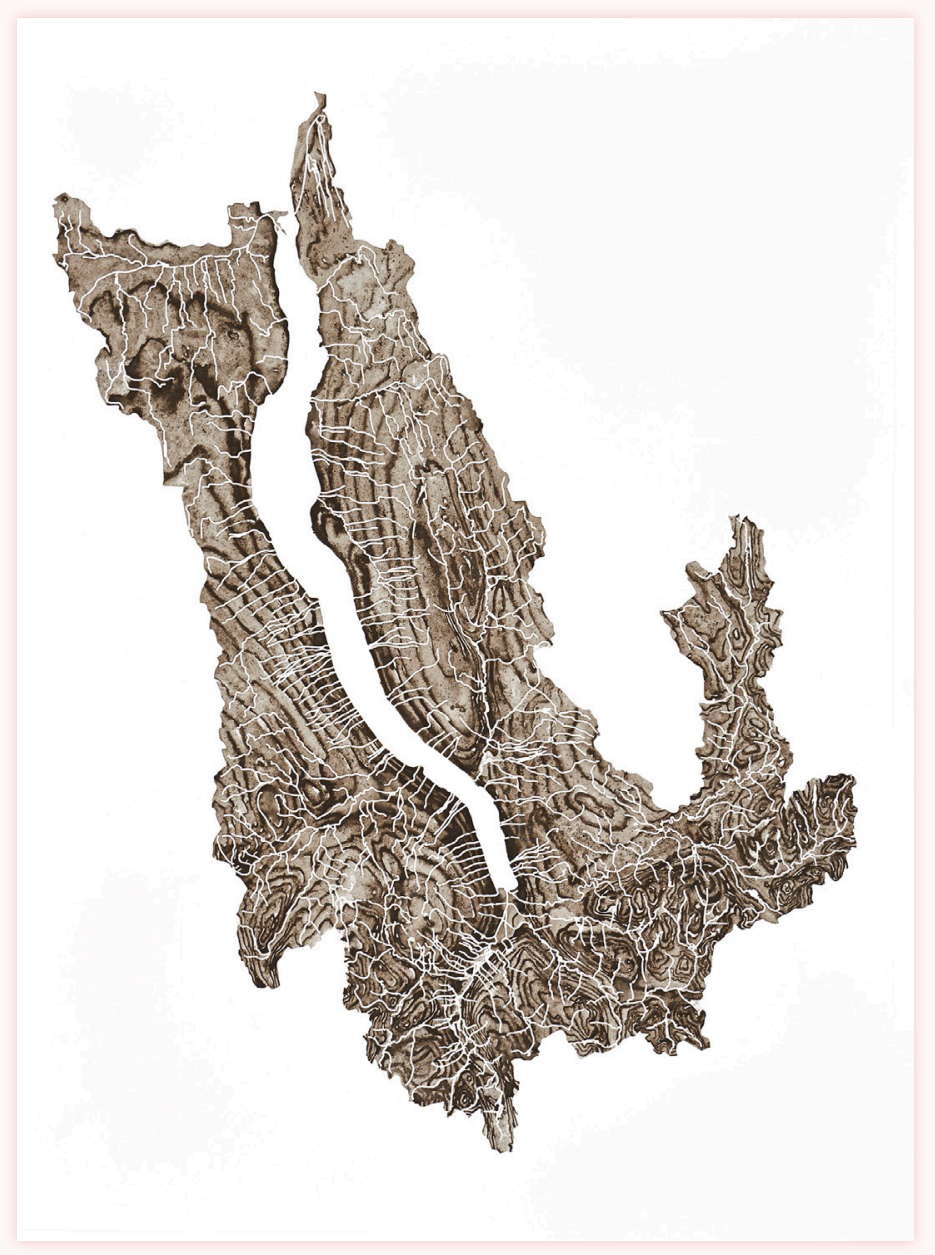

Cayuga Lake, 2017. 29in × 21in, ground rock, water, and gum arabic on paper.

the patterns of nature and reframe community boundaries around vital bioregional relationships.

The fractal geometries of river networks resemble the netted venation of leaves and insect wings, the bronchial tree that allows us to breathe, and the circulatory system that channels blood through our veins and arteries. The linear patterns of topographic data, which describe the outermost layer of the Earth, resemble the textures of wood grain, the growth lines of tortoise shells, and the contours of our own outermost layer, the epidermis.

I am often surprised by the visual correlations that emerge in my work. In speaking with various audiences, I've been told that the abstract forms in my maps of streams feeding the Delaware River are reminiscent of fetal life support systems and that the shapes in my Finger Lakes maps resemble female genitalia. Though I had never considered

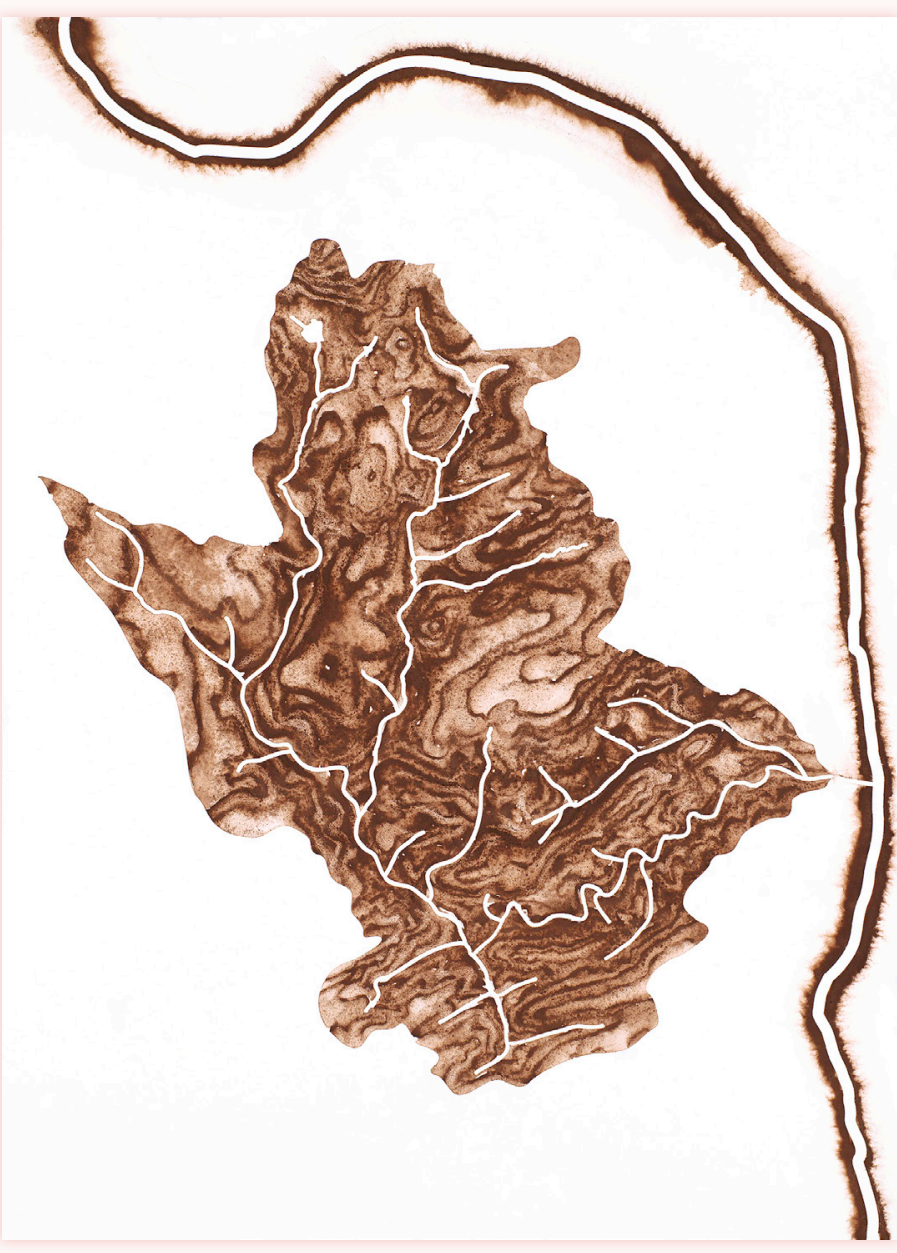

Tinicum Creek, 2017. 15in x 11 in, ground rock, water, and gum arabic on paper.

either of these parallels, I find these vital anatomies of human reproduction to be beautifully appropriate metaphors for the creative, life-giving force of our freshwater networks.

By exposing such similarities, my maps remind us that in a world that often seems chaotic, there is a natural order to which we belong and to which we are responsible. These maps offer an opportunity to reorient, to identify with watersheds, and to find meaning in our inherent interdependence.

\section{REFERENCE}

Turner, Elizabeth Hutton. 1999. Georgia O'Keeffe: The Poetry of Things. Washington, DC.: Yale University Press. 


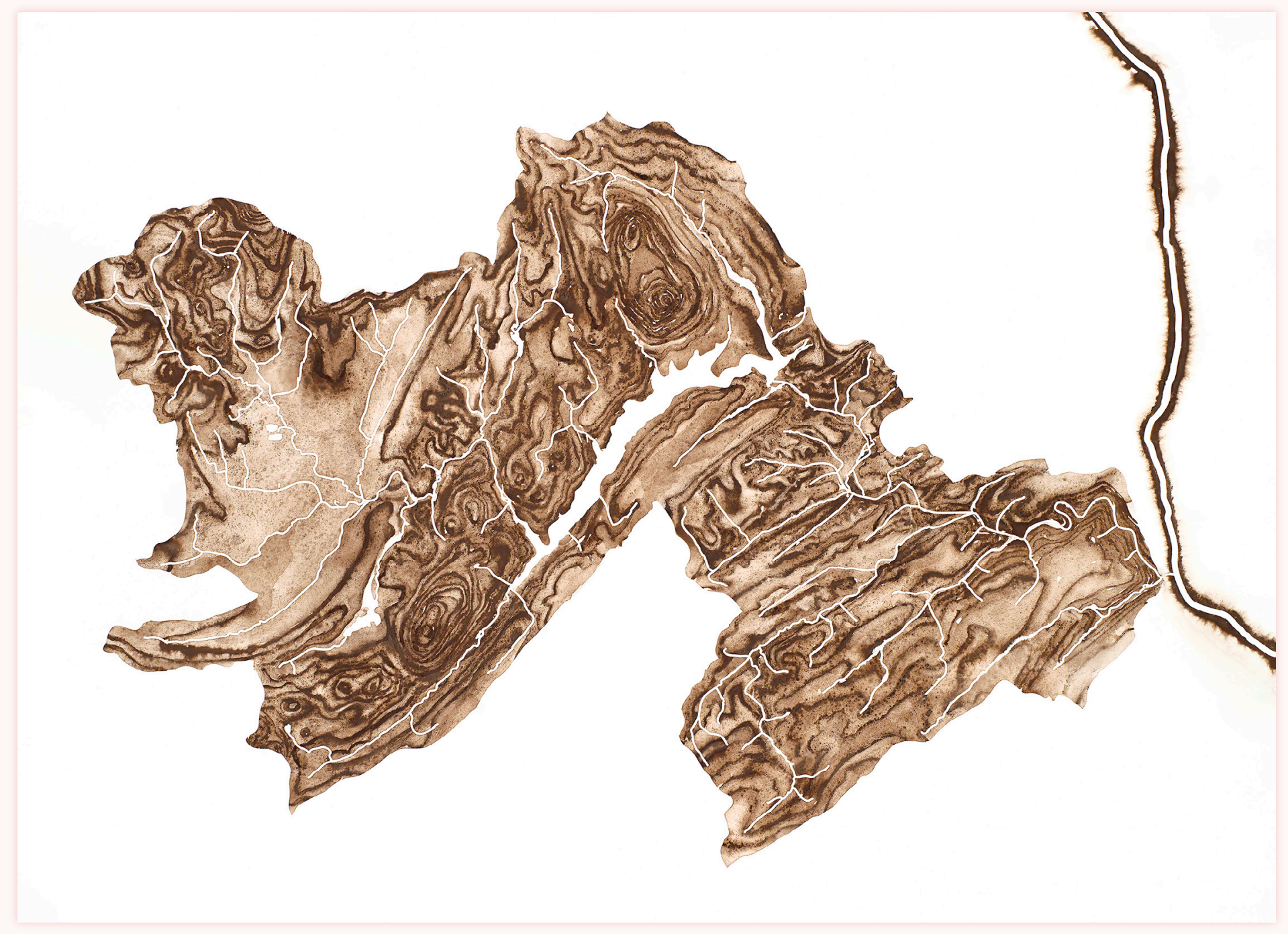

Tohickon Creek, 2017. 21 in $\times$ 30in, ground rock, water, and gum arabic on paper. 